Boise State University

ScholarWorks

7-1-2008

\title{
Writing Toward Readers' Better Health: A Case Study Examining the Development of Online Health Information
}

Russell Willerton

Boise State University 


\title{
Writing Toward Readers' Better Health: A Case Study Examining the Development of Online Health Information
}

\author{
Russell Willerton \\ Boise State University
}

\begin{abstract}
Each year, more people search the Internet for health information. Through a case study conducted at a prominent health information company, I will show that technical communicators are well suited to contribute to the development of online health information. Like other technical communicators, online health information developers must make rhetorical choices based on audience needs, function within specific social contexts, and work through challenges of writing, editing, and project management.
\end{abstract}

Bio

Russell Willerton is an assistant professor of technical communication at Boise State University. His research on document design and white papers has been published in the Journal of Technical Writing and Communication and Technical Communication.

\section{INTRODUCTION}

According to a survey conducted by the Pew Internet \& American Life Project (Fox, 2006), 80 percent of American Internet users, or 113 million adults, have searched for information on at least one of 17 health topics such as diet and nutrition, sexual health, and specific diseases or medical treatments. Harris Interactive (2003) also reported that 80 percent of patients surveyed consulted online sources for health information, adding that "The vast majority of them report that the information they find enhances their understanding of their health problems, has an impact on how they manage their overall health, affects how they communicate with their doctors, and improves their compliance with prescribed treatments" (Harris Interactive, 2003, p. 2).

Unfortunately, as the Pew report (Fox, 2006) points out, Internet users often fail to evaluate the sources and dates of the online information they consult. Although reported cases are rare, emotional distress and even physical harm may befall those who act on bad information or who misunderstand or misapply information that they find (Crocco, Villasis-Keever, \& Jadad, 2002). Only 3 percent of respondents to the Pew survey said they or someone they know had been seriously harmed by following the advice or information they found online, but that small number of respondents extrapolates to 3 million adults who might have faced some type of harm or difficulty (Fox, 2006, p. 8).

Because so many people are searching Internet sources for health information, the question of how to design accurate, useful, and usable online health information is clearly an important one for technical communication researchers and practitioners to address. Along these lines, some recent studies investigate types of online health information and how consumers use and evaluate them. For example, Oermann \& 
Pasma (2001) showed that information on how to judge the quality of care provided by a doctor, hospital, or long-term care facility is generally easy for consumers to read and understand when it meets standards for content and design set by the Health Information Technology Institute, a non-profit organization focused on health and information technology. Oermann and Pasma (2001) write that quality of care information is well suited for distribution online because it is not likely to be provided to patients when they are seeking care for an illness. Freeman and Spyridakis (2004) examined factors that affect readers' judgments of the credibility of online health information. Their study confirmed strong relationships between readers' evaluations of sources of information and their evaluations of the information provided by or attributed to those sources. They also found that readers may judge online medical information less critically if it interests them, and that readers with greater Internet experience may judge credibility more critically than those with less experience (2004, p. 257). Tjora, Tran, and Faxvaag (2005) studied a group of patients who used a secure online system called MedAxess to communicate with their primary care physician. They found patients experienced easier access to their physician by using MedAxess instead of using the telephone or traveling to the doctor's office; patients tended to solve specific problems that they felt were too complicated to explain on the phone or that required some interaction back and forth between patient and doctor; patients did not worry about the security and confidentiality of their medical information. However, patients felt the log-in process was awkward and a barrier to use, and some patients preferred plain email instead of MedAxess.

So far, only a handful of studies describe how online health information is created. One article in that vein is an overview of how the National Cancer Institute has gathered user input over several years and modified its main website in response to this input (Grama et al., 2005). Another is Williamson (2005), which describes how user needs can be addressed through research and planning before a health website appears online. A recent book by Miriam Locher, Advice Online (2006), provides insight on health information provided by a particular website that invites questions and provides responses. However, Locher's study focuses on textual features of the advice that is given and not on the processes through which that advice was formulated. A recent study of German question-and-answer websites, somewhat similar to Locher's but smaller in scale, showed that experts used more medical terms in the answers they provided when readers used more of them in their questions (Jucks \& Bromme, 2007). The online Journal of Medical Internet Research is an "international scientific peer-reviewed journal on all aspects of research, information and communication in the healthcare field using Internet and other eHealth technologies" ("Scope," n.d.). While many articles in $J M I R$ concern online health information, most focus on how that information is used and not on how it was created or designed.

In attempt to add to this initial understanding of the design and creation of online health information, this article presents a case study of writing at a leading provider of online health information. I will show that online health information, like other forms of technical communication, requires writers to make rhetorical choices based on audience needs, to function within specific social contexts and work with subject matter experts (SMEs), and to carefully think through challenges of expressing ideas correctly and managing work efficiently. At the same time, I will show how the goals of online health information producers can positively affect the relationships between writers and SMEs, and I will show how the continually changing body of evidence-based medical knowledge affects the ways writers produce online health information. As the need for accurate and usable online health information continues to grow each year, technical communicators and academic technical communication programs are well suited to contribute to the development of online health information.

Naturalistic studies of writers producing particular types of texts (e.g., Dautermann, 1997) provide insight into the rhetorical processes and organizational forces that shape those texts. Cynthia Ryan's case study (2005) involving the women's health magazine MAMM and Roger Munger's article (2000) on paramedics' run reports are among the few recent works in our field on medical and health discourse that include direct observation of people creating medical and health-related documents. While the run reports are produced and used by trained medical and paramedical personnel, the articles in $M A M M$ were created for a consumer audience by writers with varying levels of knowledge about and experience with breast cancer. The online health information from the company in the following case study is produced by writers and editors from a variety of backgrounds: some were trained in nursing or other health professions, while others have backgrounds in other fields, yet all content must pass physician review. Thus, the space in which this 
company operates is in some ways between the spaces described by Ryan (2005) and Munger (2000), of medical professionals and professional communicators. As the World Wide Web becomes a more important source of health information for consumers and medical experts alike, this space may offer new and expanded opportunities to technical communicators.

Although scholars of technical communication describe the field in a variety of ways, these three aspects are used frequently: technical communication is a rhetorical endeavor that requires specific attention toward the audience (Peeples, 2003; Ornatowski, 1997; Whitburn, 2000); it occurs in specific social contexts (Lay et al., 2000; Markel, 2007); and it requires communicators to use cognitive skills to solve problems (JohnsonSheehan, 2005; Anderson, 2007). Answers to these research questions will provide insight about how each of these elements of technical communication affects work at the case study site:

- How do writers and editors collaborate with reviewers who are physicians?

- How do writers and editors envision their audiences and tailor health content for them?

- What cognitive processes are involved with creating health-related content for online delivery?

In the following section, I will describe my research methods. Next, I will present and analyze the results of my research. Finally, I will discuss the implications of this study for technical communication pedagogy.

\section{CASE STUDY SITE AND RESEARCH DESIGN}

As I sought an opportunity to observe how online health information is created, the company that I'll call Alturas provided a sample of health information developers whom I could observe in situ within the context of their regular work. Alturas is a prominent producer of health information in a variety of print and online formats. The company provides content to consumer health portals, health insurance companies, disease management companies, hospitals, nurse call centers, and medical practices, to name a few types of clients. These organizations then provide this health information to their consumers.

The members of my sample (I will use pseudonyms for the participants in the study) were recruited by a division manager, Leah, and two senior executives, Helen and Tamara. Leah's group includes writers, copy editors, and editor-managers; eight of them participated in the study, along with Leah. Leah, Helen, and Tamara sought volunteers who represented a variety of roles within the team and who had a range of experience at Alturas. Four were writers, one was a copy editor, and three were editor-managers. Some had worked at Alturas less than two years, while others had worked there more than a decade. Two had nursing degrees, two others had master's degrees in science, and the rest had studied in history, English, journalism, and psychology. One of the group had, in addition to other degrees, a master's in technical communication; another was a part-time graduate student in technical communication. Participants signed IRB-approved consent forms, allowing me to observe their work and to tape-record interviews. While Alturas provides a wide variety of content in print and online formats, the employees I observed are involved primarily in producing information accessed online through a web browser.

The medical review team, which must approve a piece of content before it is published, includes licensed physicians who work with content development divisions throughout the company; I talked to two physicians from that group, Grant and Gretchen. Alturas' content covers a wide range of topics, from relatively simple items like bunions and common colds to complex topics such as HIV, coronary artery disease, and endometrial cancer. Types of content include descriptive overviews, causes, treatments, prevention tips, descriptions of relevant drugs, and tools for making decisions on treatment.

Alturas closely follows research on evidence-based medicine (EBM), and the onsite library helps the company to stay informed about the most current medical knowledge. The foundation for their content is the same knowledge available to the medical community at large. As Sackett and Rosenberg have written of EBM, "The ascendancy of the randomized trial heralded a fundamental shift in the way that we establish the clinical bases for diagnosis, prognosis, and therapeutics. The ability to track down, critically appraise (for its validity and usefulness), and incorporate this rapidly growing body of evidence into one's clinical practice has been named 'evidence-based medicine"' (1995, p. 620). Denny writes that EBM research follows these 
steps: "the formulation of a clinical question, a search of the literature for relevant clinical articles, an evaluation of the appropriateness of the evidence thus gathered, and the application of useful findings. Of course, some forms of evidence are considered more appropriate than others and the most highly prized is evidence derived from randomized, controlled clinical trials" (1999, p. 6).

Denny points out (1999) that EBM tends to maintain a separation from complementary and alternative medicine (CAM), which includes treatments such as traditional Asian medicine, aromatherapy and herbal medications, acupuncture, shiatsu and yoga. While some efforts are underway to make the study and practice of CAM more scientific and evidence-based (Cooper, 2004), EBM will most likely reflect the points of view of doctors who conduct and rely on scientific studies within the EBM paradigm (Denny, 1999).

In addition to the on-site library providing access to the latest knowledge of EBM, writers at Alturas learn about their subject matter from physicians and specialists who work for Alturas to review health content. While the practice of having physicians and medical specialists review online health content has practical benefits, such as helping to ensure that readers receive accurate and appropriate information, it also helps online health information providers like Alturas maintain accreditation from URAC and other groups. The most stringent accreditation is offered by URAC, an accrediting body overseeing several aspects of healthcare services in the U.S. URAC's standards, which Alturas meets, state that online content should be reviewed by a minimum of two health content reviewers, and that at least one of them should possess expertise in the specialty area relevant to the condition under review (URAC, 2007). URAC accreditation teams review a provider's content and conduct an onsite investigation of management and quality control practices. URAC accreditation process is more stringent than that offered by the Health on the Net (HON) Foundation. The HON Foundation is an international non-governmental organization based in Switzerland, and its code of conduct requires that information on medical and health websites be given "by medically trained and qualified professionals unless a clear statement is made that a piece of advice offered is from a non-medically qualified individual or organisation" (2007). Another group, the Internet Healthcare Coalition, provides a code of ethics (2006) for information providers and tips for consumers about how to evaluate online health information, but the group does not certify or accredit information providers.

\section{Design and Methods}

Because my research questions were well-specified, I developed a framework that prestructured (Miles \& Huberman, 1994, p. 83) my case study. This study is descriptive because it attempts to preserve the "natural setting" I observed and to provide a "rich understanding" (MacNealy, 1997, pp. 44-45) of how online health information is produced at Alturas. I designed a naturalistic case study, in which many hours of observations in situ within the context of the informants' regular work would be supplemented by interviews. Over the course of eight weeks, I shadowed my informants at prearranged times, observing them and taking notes as they went about their writing and editing duties, and participated in meetings. I then typed out my notes from each session. I later interviewed each informant to further discuss his or her work, to look at specific examples of online health content, and (with the exception of Leah, the division manager) to gather responses to my survey questions (see Appendix). Tape-recorded interviews were later transcribed. Each transcript and set of notes received a two-letter identifier for tracking purposes; these identifiers will be used in the results section below.

I offered to provide a research exchange (Adler \& Adler, 1987, p. 40) as a way to reciprocally benefit Alturas and to acknowledge the privilege of conducting research there. Leah, Helen, and Tamara agreed to let me give a summary presentation at the conclusion of the project. This presentation included results from my observations as well as a bibliography of resources based on topics of interest identified through the survey.

After concluding my observations, I came back to my notes and identified information that related to my research questions. I followed a similar pattern with the transcripts of the audiotaped interviews. Periodically, I wrote analytic research memos (Glesne, 1999) that focused on the three key research questions. Following Lincoln and Guba (1985), I used member checking to ensure the accuracy of my interpretations. I gave my informants the opportunity to shape this document by sharing a draft with them, and I have incorporated many of their comments and clarifications into this article. 


\section{RESULTS}

\section{What factors help writers and editors collaborate with reviewers who are physicians?}

In the field of technical communication, it is often expected that subject matter experts (SMEs) such as programmers and engineers will treat writers as inferior (see Dragga, 1993; Jeyaraj, 2004; Lee \& Mehlenbacher, 1997; Savage and Sullivan, 2001). Programmers and engineers tend to receive higher salaries and to possess a stronger degree of professional status than technical communicators. Because physicians and medical specialists receive so much training, earn higher salaries, and tend to be regarded highly by society, I wanted to know whether the writers at Alturas would experience difficulties with their subject matter experts similar to those faced by some in the technical communication community. At Alturas, content must be reviewed both by a physician-reviewer, who often has experience as a general practitioner, and by a specialist-reviewer who practices a specific area of medicine.

On the whole, it appears that writers at Alturas do not face the negative treatment that technical communicators are known to receive from some subject matter experts. Whereas some subject matter experts view creation of documentation as an activity that takes them away from other work on their companies' products (Lee \& Mehlenbacher, 1997), physician-reviewers at Alturas know that documentation is the company's chief product. This premise appears to affect the relationships between writers and reviewers. I found three factors influencing the positive relationships between writers and physician-reviewers: shared goals, a flat hierarchy, and a high frequency of interaction. Each of these factors is related to and supports the others. These factors help ensure that writers and editors are treated as fellow professionals and not as support personnel, which can be the case for some technical communicators (Flammia, 1993, p. 128).

The concept of shared goals was first brought to my attention by Thomas. Thomas is a writer with a background in journalism and corporate communication. He said that in his experience in the newspaper business, many co-workers were concerned about their egos. Employees were not always working toward a common goal; sometimes one person would sabotage another's efforts. At Alturas, he said, the physicianreviewers are focused on the result and what it means to the patient (AL 2). The common goal at Alturas is to provide useful information that helps readers make decisions about their choices in medical treatment and day-to-day health. Grant, a physician-reviewer, said the shared goals of the medical review staff at Alturas parallel those for his own private practice. He said several of the physician-reviewers have a consultative style of practicing medicine, in which they like to help patients make decisions. That consultative "stamp" is on a lot of Alturas' content (AG 2).

Another factor that helps the writers and editors at Alturas work with the physician-reviewers is the relatively flat hierarchy between the groups. Physician-reviewer Grant told me that at Alturas, the writers and the physician-reviewers are equally important. I discussed this research question with another physicianreviewer, Gretchen. She pointed out that in medicine, the number of instances in which you need a strong hierarchy between a physician and his or her team members is relatively small. "If there is a fire, you need somebody to be in charge. If you are operating on the patient and the patient might bleed to death, you need somebody to be in charge, although sometimes that prevents people from asking questions" (AE 1). Thus, a flat hierarchy between writers and physician-reviewers helps all parties at Alturas complete their assigned tasks and pursue the company's goals collaboratively. As evidence of the flat hierarchy, several writers told me (and I observed) that physician-reviewers interact with writers and editors using their first names instead of "Dr." Additionally, the offices of physician-reviewers who work in the Alturas building are identical to those of the writers and editors. In discussing the candor and openness in the relationships between writers and reviewers, physician-reviewer Grant stated, "Sometimes a writer will say to me, 'I don't think we should put this in, because it doesn't help.' So we'll have a discussion about it. But it's the writer's job to decide what to say and how to say it. As long as they're medically accurate, I'm fine with that" (AG 4).

A third positive aspect of the relationship between writers and physician-reviewers is frequent interaction. Several of the physician-reviewers work in the Alturas building, although some do work remotely. In addition to their shared work during the review of content, writers and physician-reviewers meet or talk during the planning phase for each document; they all get the same research packets provided by the Alturas 
medical library. Physician-reviewers onsite meet with writers frequently to discuss and evaluate items published in medical literature and medical news sources. Alturas brings all the physician-reviewers to the building once or twice each year for workshops and other activities. Writer Dawn commented that these meetings reinforce teamwork and encourage a more personal relationship between writers and reviewers (AE 11). By making time to work with writers and editors, understanding the processes writers and editors follow, and respecting writers' and editors' roles, the physician-reviewers at Alturas make many of the positive contributions requested of SMEs by technical writers responding to the survey by Lee and Mehlenbacher (2000).

Just as they interact with physician-reviewers, writers also receive support from their editor-managers. The editor-managers participate in planning sessions and serve as content reviewers. As an editor-manager named Denise put it, she is a coach as well a content instructor (AR 2). Denise also said she helps writers work within the company's standards and sometimes to adjust rules in order to create content that will be useful to the audience. About 95 percent of the topics will easily fit within existing processes, but the rest require discussion and collaboration to find a process that will work best for a particular topic (AT 1). Editormanagers also provide support with project management, which will be discussed later in this article.

Writers have less interaction with the specialist-reviewers (physicians practicing in a particular medical specialty). A specific group at Alturas manages the communication between writers and specialists because the specialists' time carries a high financial premium, and because the specialists' work is done remotely. The non-specialist physician-reviewers sometimes interact with the specialists to discuss a comment that has been made during the review process. Writers are able to communicate with specialists through e-mail and conference calls. The physician-reviewers help balance medical accuracy (to which the specialist reviewers contribute prominently) and the needs of Alturas' audience. Physician-reviewer Grant described how the editorial process affects physician-reviewers and specialist-reviewers:

We [the core medical team at Alturas] retain the editorial rights.... We used to defer to the specialists more, but now we realize, we're the ones who are here and who know better what the consumer needs. Their job is to provide a review. Our job is to interpret that for the consumer. If we think it doesn't translate, we won't add it. Sometimes that means we have to go back to them and say, we didn't make your change. But I think most of them understand why we do what we do. You want to defer to the specialist, but you have to make sure it helps the reader. (AG 3)

\section{How do writers and editors envision their audiences and tailor health content for them?}

As was previously discussed, evidence-based medicine is the foundation for the content created by writers and editors at Alturas. In terms of shaping content for their audience, I observed four factors that tend to affect writers' and editors' choices: personal experiences of the writers and editors, the clinical experience of the physician-reviewers, client comments, and knowledge shared among team members.

Those writers and editors with experience in nursing or other allied health professions draw on it regularly. Kathryn, a writer and registered nurse, said her clinical experience has a "huge" impact on her writing. For many topics she writes about, she said, "I can picture a patient in my mind-remember how we did it, what the steps were, what interaction I had" (AM 5, 3). Kathryn maintains her nursing license and also keeps up her clinical experience by working shifts in a hospital. Editor-manager Denise, also a registered nurse, values her own first-hand experiences as well as those of her writers. She mentioned that she was particularly pleased to have a newly hired writer working on mental health topics; this writer has a degree in psychology and experience working with special-needs individuals. Denise said, "It's easier when people are engaged in their subject matter. A writer who has an educational and work background in the mental health field is more likely to write information with the right tone to engage the reader" (AR 2).

The physician-reviewers' clinical experiences have a strong influence on the online health content at Alturas because they can shape documents going through the review cycle. While the writers have access to the latest information on each subject, the physician-reviewers provide what Grant called "clinical wisdom" (AG 3). 
This is a preprint of an article whose final and definitive form has been published in the Technical Communication Quarterly $17(3) \subseteq$ 2008 Taylor \& Francis; Technical Communication Quarterly is available online at:

http://www.informaworld.com doi: 10.1080/10572250802100428

Dawn, a writer, said of one of her physician-reviewers, "She has clinical knowledge that is priceless. She has a good feel of what patients need to know" (AE 7, 8). Grant explained the nature of his insights about the Alturas audience:

I've been in practice 13 years. The thing that I get that the writers don't get is feedback on what I'm doing. Some feedback is verbal, and other feedback is visual. If I'm talking to you about the pathophysiology of how ACE inhibitors work [to treat high blood pressure] and your eyes start to glaze over, I understand that you are not grasping it, and that I need to change how I say things....

When the writers read information and try to figure out what to write, it's hard for them to know what to write because [for the most part] they haven't sat in front of a patient and tried to decide, what is it that I want this person to know? If this patient is going to remember three things when they leave this office, what are those things? It's not that an ACE inhibitor blocks a protein; it's that it can make them not die of heart failure. (AG 1)

Another way in which writers, editors, and their managers learn about the audience is through comments from Alturas' clients and their consumers. The content of the Lucy Answers online health website studied by Locher (2006) is almost entirely created in response to specific requests. Although Alturas, in contrast, does not have the question-and-answer format used by Lucy Answers, comments from Alturas' clients form an important source of ideas for new topics to pursue and for specific opportunities to provide updated information. Alturas' clients comprise one of several user communities (Barker, 1998) who employ the company's content regularly. Paige, an editor-manager, explained that every comment from a client or consumer goes through triage by a committee of editor-managers and a physician-reviewer. This committee formulates a response to each client and makes a decision on whether to change Alturas' online health content. This internal process for accepting and processing user feedback (Nielsen, 1993; Barnum, 2002) helps Alturas to better understand the audience's needs, and it helps Alturas to provide content that is more useful and usable. Paige said that in a period of about 3 months, about 100 comments had been addressed, and many comments led to changes and updates in Alturas' content (AV 1).

Shared knowledge and understanding are a fourth influence on the online health content at Alturas. Alturas emphasizes collaboration among its employees. The Alturas building has many meeting rooms that are frequently filled with discussions and group work sessions. To paraphrase what I heard on more than one occasion at Alturas, "Many eyes make the content better." I have already mentioned the collaboration of writers, editor-managers, and physician-reviewers during the planning process for each document. In addition, the writers meet together frequently to discuss their work, as do the copy editors. The copy editors sometimes give short presentations to the writers. The frequency of collaboration creates an environment in which writers and copy editors share information and work toward similar goals for the content they produce.

\section{What cognitive processes are involved with creating health-related content for online delivery?}

As I sought to research the cognitive processes involved with creating health-related content for online delivery, I was interested in how the writers and editors approach their tasks — what mindsets did they adopt? How did they think about their work as they went about it? Four main processes emerged through my observations: focusing on roles and responsibilities, managing projects, learning to embrace the flexibility offered by hypertext, and monitoring accuracy and consistency among documents. While these processes were important for those individuals I observed at Alturas, they also have practical applications for writers and editors creating documents in a variety of settings (e.g., Hackos, 1994; Ament, 2003)

Focusing on roles and responsibilities. Writers and editors must concentrate on the task at hand and avoid work unrelated to that task. The amount of content Alturas produces is vast - many thousands of electronic documents. In part, this need to focus on roles and responsibilities stems from the wealth of information Alturas has created. The writers at Alturas use an XML tool for their authoring work; the content they produce goes to many clients, each of whom will interpret the styles in the document type definition (DTD) differently. While employees at Alturas test their content to ensure that web browsers will display it properly, they know that they must relinquish some control over how the text will appear on the end-user's screen. Their roles are to create quality content, or input, while their clients will have their own interpretations for 
the format, or output (see Ament, 2003, p. 3). Alturas also has a company-wide commitment to update all of its topics on a regular schedule. Because the amount of content is so great, writers and editors assigned to updating documents must focus on the medical information in each document more than the style and structure. Other writers and editors have primary responsibility for style and structure, so each group must respect the other's roles. As writer Dawn stated, she and the other writers are aware that they only have time to do the assigned tasks before moving to another document (AE 6). Anne, a copy editor, stated that there are points at which both writers and editors sometimes feel constrained by the content development and review process. However, Anne acknowledged that changing the process by stretching their resources even farther could have other domino effects that might offset any gains (AK 1).

Managing projects. Project management is another key cognitive activity. Alturas updates thousands of online documents regularly, and new documents are always in development. As writers, editors, and content managers think through their work, they follow the processes and timelines established through the project management process. Denise, an editor-manager, summed up the importance of project management: "Our team lives and dies by timelines. Timelines help everyone keep their work on schedule" (AR 2). Members of the project management team consult with writers and editors frequently. The team also maintains an online system to track the content developers' work. In addition to the timelines maintained in the online system, both the writers and the copy editors follow processes that they have developed for their respective duties. Writers manage parts of their own work by a creating a work plan for each document they create or update. As writers and editors at Alturas think through their work, they are aware of each document's progress within its appropriate processes, and they consider how their tasks will affect their colleagues.

Another aspect of the need for project management comes from the intangible nature of online documents. Without specific processes to identify particular online documents for review, such documents are likely to stay out of sight and out of mind. They are not visible on a shelf like a book is, and a database of documents does not have a specific beginning and end. Editor-manager Teresa, who has worked on some books that Alturas produces, described one of the differences between working in print and working with online documents: You can look at a book and say that it's finished, but the online database of documents is never finished ( $A B$ 13). For writers and editors to understand that progress is being made, it is important to evaluate each phase when it is completed so information developers know whether a project has been successful (Hackos, 1994).In addition to being intangible and online, Alturas content is so vast that as one phase of content development is winding down, another phase has already begun. The staggered project schedules that facilitate work on documents in the database also ensure that other documents are always in the queue to be updated and edited.

Learning to work with hypertext. A third process involves learning how to incorporate links to other pieces of content and managing the content's structure. Sara, a writer, said one helpful aspect of writing online is that "you don't have to necessarily explain every term because you can link to information.... Instead of having to explain what a prostaglandin is, you can link to it. Because not everybody is going to want to read that and know exactly what a prostaglandin is up front. But if they want to learn more, they can" $(\mathrm{AC} 2,3)$. Alturas also provides some online quizzes and some graphics to which writers can link. Writers may request graphics if none are available for a particular topic. Writer Thomas, who previously worked in journalism and corporate communications, is used to writing according to a layout, to fit that physical space. When he was writing newsletters, he was encouraged to keep it "long enough to inform people, but short enough for them to read before they toss it in the garbage." He now prefers the flexibility of writing online (AL 4). Editor-manager Teresa pointed out that the space in the books is limited, because pages must be added in multiples of four, and an increase in pages leads to an increase in the cost (and eventual price) of the books. Teresa said, "The space limitations online, there really aren't any. You can put anything in there. Here [in one of the books] we just had to be much more judicious about what are the absolute key elements they need to know" (AB 2). In a printed book, Teresa continued, the proximity of one element to another can affect how readers understand the information; online the information is structured and controlled somewhat more easily (AB 4). 
Monitoring accuracy and consistency. A fourth cognitive process involved with creating online health information at Alturas involves monitoring accuracy and consistency among documents. To ensure that content is accurate, writers, editors, and reviewers must stay informed about recent medical news and literature; the medical librarian, writers, and physicians review medical news daily to identify any information that needs to be added to or updated in Alturas' content. Maintaining consistency presents additional challenges. As writer Dawn said, "Consistency is hard to achieve with lots of writers, lots of documents, and not a lot of time" (MD 2). Some medical facts that may be especially important to keep consistent among many documents include dosage recommendations for over-the-counter medicines, recovery times after certain procedures, names of prescription drugs, and recommendations for nutrition and personal care. For example, in working on one dental health topic, writer Thomas learned from editormanager Denise that the American Dental Association had changed its recommendation for the number of times for daily tooth brushing. Because the old recommendation appeared in several documents, steps had to be taken to update all of them (AD 4). In another instance, editor-manager Paige said that when the American Heart Association published new guidelines for chest pain, calling 911 and the use of nitroglycerin, approximately 20 documents were revised to reflect this and keep the content medically accurate and consistent (AV 2).

Employees at Alturas have a high level of familiarity with the content of their documents, and they are likely to be able to identify the documents that would need to be updated when a particular piece of new information becomes available. However, this knowledge of how new information affects existing documents is often tacit and not explicit; some people at Alturas refer to it as tribal knowledge. This tacit knowledge is important because new evidence-based medical information can affect the content of many documents, not just the one(s) a writer is working on. Generally speaking, tacit knowledge made explicit has potential to increase not only the accuracy of a document, but its value as well (Hughes, 2002). At Alturas, making this tacit knowledge explicit could lead to specific results in a reader's life: for example, a consumer might use this knowledge to take an appropriate dose of nitroglycerin after suffering a heart attack.

Because of the large number of documents that are going through the update process at any given point in time, formalized processes for ensuring accuracy and consistency are essential. Recently Alturas increased its already strong attention to accuracy and consistency by hiring a consistency coordinator, Alyssa. Alyssa manages an online system to which anyone at Alturas may submit a concern about accuracy or consistency within a single document or a series of documents. This system helps codify tacit knowledge and to make it available to employees throughout the company (Wick, 2000; Applen, 2002). Alyssa meets with physicianreviewer Grant to determine the urgency of each issue, and then she searches all of Alturas' published content to see where certain words and phrases appear. She then sends the results of her search to a writer or editor assigned to work on it. Alyssa said the consistency initiative started as a quality-control function, but that now it is affecting research and development activities and new product development. The eventual goal is to "establish one-to-one relationships" among medical facts and make the medical review process more efficient (AZ 1).

\section{Implications for Technical Communication Pedagogy}

Through observations and responses to the survey (see Appendix), I have identified seven ways in which professional associations and academic programs in technical communication might support and educate professionals who create online health information. While it is likely that some of these suggestions are already in place in many programs that do not have developers of online health information among their constituents, I will list them below to point out how they apply to the creation of online health information.

Outreach. First, technical communication professionals should reach out to local employers and educate them about our academic classes and the professional technical communication community as a whole. For some people outside the field, technical communication can be associated with a legacy of poorly written technology manuals. Even though Alturas' city is served by an academic technical communication program and a chapter of the Society for Technical Communication (STC), many people I met at Alturas were unfamiliar with the field and with the range of activities in which technical communicators are involved. I recall one particular meeting of writers, editors, and managers working on a special project. The product manager who convened the meeting knew about my research project and asked the group, partly because I 
was attending, if they considered themselves technical writers. Only Anne, a copy editor who has taken several graduate classes in technical communication, said yes. The rest did not consider themselves technical writers. This group associated the term "technical" with subjects like information technology and mechanical pursuits. They felt that health and medicine are artistic and intuitive endeavors-that some aspects may be "technical," but not usually. Technical writing is what they do at an electronics manufacturer in the region, some said. Although writers and editors at Alturas do many of the tasks associated with technical communication, I did not mention that at the time because I did not want to affect or stifle the group's discussion about the definition of technical communication. I did point out some of the difficulties of naming academic programs and designing curricula in technical communication. Terms such as professional writing, professional communication, and scientific and technical communication are among those used, I said (MB 2). In a presentation to Alturas after I had completed my research there, I pointed out that the STC has several special interest groups (SIGs) that focus on topics that apply to the company's work. Some of these SIG topics include international communication; management; usability; instructional design; and environmental, safety, and health communication.

If technical communication is to benefit writers not currently affiliated with the field, such as some of those at Alturas, academics and practitioners should promote the fact that the field is supported by research in a variety of cognitive and rhetorical endeavors, and that organizations such as STC have knowledge about facets of the communication process that would be valuable. Of the eight writers and editors I interviewed, five were members of the American Medical Writers Association (AMWA). Some AMWA members found benefits in the training programs the group offers, but many acknowledged that a large portion of AMWA members are writing complex documents for highly specialized audiences unlike Alturas' general consumer audience. Online information development gets little attention through AMWA publications and conferences; STC could be a resource in this area and others. After reading a draft description of the project meeting I observed, editor-manager Denise, who participated in that meeting, aptly described the group's perceptions of the field of technical communication and pointed out some areas in which the field's public persona might expand.

From my point of view, what we do at [Alturas] is write information in a manner that helps people make better health decisions. If the writing we do is going to be included in the field of "technical writing," the technical writing field needs to expand beyond what is perceived as "writing the facts" (as in how a DVD player works) to how to engage and motivate people to think about their personal choices. As I said before, maybe the "motivational/behavioral change aspect" of the type of writing we do at [Alturas] could be incorporated as a substantial part of the technical writing programs to make such programs even more effective. (MZ 3, emphasis added)

Many discussions of outsiders' views of technical communication focus on one of two issues: whether knowledge of software tools is essential to the field, and whether the field is a profession (Davis, 2001; Hayhoe, 1998; Kynell-Hunt \& Savage, 2003; Kynell-Hunt \& Savage 2004). For Denise and others at Alturas, however, the definition of technical writing was associated instead with writer's subject matter and goals. One of Spilka's (2002) suggestions for becoming a profession is to embrace the diversity among varying technical communication roles, activities, and organizations. Expanded relationships with companies like Alturas could give the field of technical communication greater visibility, and they could help writers at such companies improve their opportunities as knowledgeable professionals.

Critical thinking. Second, technical communication programs and the field at large should teach and discuss critical thinking. While critical thinking may be defined in any number of ways, at Alturas the term refers to analyzing the source and quality of a piece of information (such as a medical journal article or an article from a medical news service), extracting pertinent information from that source, and applying that information to Alturas' content. This is in keeping with Alturas' commitment to keeping up with advances in evidencebased medicine. Physician-reviewer Grant said that some of the most effective writers he works with can read something, make good inferences, and "take it to the next level" by making connections among documents in Alturas' online database or within the subject matter being discussed (AG 4). Writers and editors working with health information are likely to do a lot of reading, and much of it is likely to be written for experts in health and medicine. Classes and projects involving secondary research provide opportunities 
This is a preprint of an article whose final and definitive form has been published in the Technical Communication Quarterly 17(3)@ 2008 Taylor \& Francis; Technical Communication Quarterly is available online at:

http://www.informaworld.com doi: 10.1080/10572250802100428

to develop these skills. Writer Dawn, who earned master's degrees in both plant biology and technical communication, commented that a technical communication class she took on research methods and evaluating sources had been particularly valuable in her work at Alturas (AE 10).

I learned more about what critical thinking means for medical professionals at Alturas when I observed a workshop led by physician-reviewer Gretchen. She began by discussing types of studies that medical researchers conduct, levels of risk for patients, and ways to describe and visualize data from medical studies. Next, audience members gathered in groups, and each group received a recent medical article to evaluate. I sat with a group that evaluated an article reporting a correlation between the use of a type of depression medication (selective serotonin reuptake inhibitors, or SSRIs) and the risk of fracture among older persons. Although members of the group did not know the article topic in advance, they were able to use the knowledge they had gained through working at Alturas and Alturas-sponsored professional development opportunities to identify key points in the article as well as characteristics about the study's participants that might have affected the results. The study reported that participants in the study who used SSRIs daily had a two-fold increased risk of fragility fractures, or fractures from falling (Richards et al., 2007, p. 188). This is the type of new information that could warrant a change in Alturas' content. Members of this group were cautious about the value of this information for Alturas' content, however. They pointed out that senior adults who deal with depression (and thus take depression medication) are likely to be physically inactive; this lack of activity could be a confounding factor, but the article did not address it. Further discussion between the group and Gretchen identified some potential consequences of modifying Alturas' content in response to this study. If Alturas reports in its content that senior adults using SSRIs have a greater risk of fragility fracture than non-users, some SSRI users might stop taking their medication, and some readers might develop a bias against treatment for depression. The group and Gretchen agreed that the best course of action would be to monitor the medical news and medical literature for further studies on the relationship between senior adults using SSRIs and the risk of fractures (AR 3).

Technology. Third, professionals and educators should teach and discuss tools and methodologies for largescale information creation, including single-sourcing. Because the human body is so complex and because advances in medicine, pharmaceuticals, and related fields continue to be made, those who work in online health information are likely to have large amounts of content to create, update, and maintain. The concept of single sourcing, or creating content in pieces that can be reused and repurposed in more than one format, is becoming especially important for writers and editors who create large numbers of documents and information products. Single sourcing has been discussed frequently at recent conferences, in technical communication journals and in books (e.g., Carter, 2003; Ament, 2003; Rockley, 2003). Along with single sourcing, content management systems are becoming increasingly prevalent in technical communication environments, and knowledge of content management practices should also benefit creators of online health information.

Project management. Fourth, professionals and educators in the field should teach and discuss project management. Because new information about health and medicine becomes available all the time, writers and editors working in this area need to be able to both plan for change and to change plans when needed. Major events such as the suspension of hormone replacement therapy (HRT) studies in 2002 and 2003 after risks proved greater than benefits (Womersley, 2004) lead Alturas to make immediate changes to related pieces of online content. Several people at Alturas showed me that some health and medical subjects change little over time and require occasional updates, while others change more often and require more frequent attention. Although Alturas has a separate project management team that coordinates content development, writers and editors may also contribute through refining existing processes and developing new ones. As new media are used to create and convey health content, communicators at Alturas and other companies will need to adapt management practices appropriately. Project management continues to be a popular topic for sessions at the STC annual conference. Academics can use the topic of project management to help students understand differences between the school environment and the workplace.

Employment. Fifth, the technical communication field should take notice of possibilities for work in online health communication. Academics could encourage students to choose science classes that relate to health and medicine, such as biology, chemistry, and anatomy and physiology. Writer Dawn, who earned a bachelor's degree in biology before pursuing her master's degrees, said that the field of biology has a "whole 
different language," and that knowledge of that language helps her as she reads information about cardiology, one of her specialty areas at Alturas (AE 10). Dawn added that any kind of science background is likely to help (AE 11). Editor-manager Paige earned a bachelor's degree in environmental science and a master's degree in biogeography and remote sensing. Writer Kathryn earned a bachelor's degree in environmental education. As mentioned previously, Kathryn and Denise trained as registered nurses. Although those with science backgrounds did not mention this explicitly, a thorough knowledge of the scientific method could also help a writer or editor's critical thinking skills and ability to analyze articles in the literatures of health and medicine.

Projects. Sixth, academics in the field should incorporate more health-related assignments, and practitioners should volunteer or partner with local health organizations. Students and practitioners communicating health information, whether in print or online formats, will get to use and develop skills in writing, editing, and creating appropriate graphics. Service-learning is another aspect that could be incorporated into healthrelated assignments. Potential partners might include a campus' student health services office, local chapters of national organizations such as the American Heart Association or the American Diabetes Association, community health clinics, or health offices at the local, regional, or state levels.

Research. Finally, members of our field could do and expand research on topics identified through question 10 on the survey of writers and editors at Alturas. The group was most interested in shorter best-practices or how-to articles, such as those provided in STC's Intercom. The topics that were selected by at least six of the eight writers and editors include best practices for plain language, online information sites, management for developing online content, interactive multimedia in online communication, online health information sites, and editing online health information. Each of the other options on question 10 was selected by at least three participants, indicating a smaller but still noticeable level of interest. While some health-related topics have been discussed in recent years at STC's annual conference (e.g., Turns \& Wagner, 2002; Zimmerman, Akerelrea, \& Buller, 2003; Freeman, 2005) and in the field's journals, more could be done.

\section{CONCLUSION}

Writers and editors at Alturas complete many tasks and participate in many activities that are familiar to members of the technical communication field: they gather information from subject matter experts, they collaborate in team projects, they use specialized software tools to create informational documents for online use, and they take great care to ensure that the information they produce is written appropriately for their audience. Writer Dawn and copy editor Anne have been able to use their knowledge of technical communication to contribute to Alturas' ongoing success in providing online health information that is accurate and easy to understand.

In addition to communication knowledge, writers and editors of online health information need the ability to use and understand the language of health and medicine. This ability may be developed through formal education, through professional development and training activities, and through on-the-job training and experience. My observations and my discussions with managers and physician-reviewers revealed several traits of successful writers and editors at Alturas, many of which correspond to a list of characteristics of successful biomedical writers (Bicknese, Connelly, Lantz, MacKay, \& Snyder, 1999a). These traits include intellectual curiosity, creativity, innovation, and the ability to work within practical constraints. Biomedical writers often write for expert audiences in areas such as regulatory writing, pharmaceutical development, and public health and policy, although some audiences will lack expert knowledge of the subject matter (Bicknese et al., 1999b). Although many biomedical writers work independently and as freelancers (Bicknese et al., 1999a), certainly the ability to collaborate is important for writers in corporate settings like Alturas.

In addition to private-sector opportunities, communicators with interests in health or medicine might pursue jobs in the public sector. The Centers for Disease Control and Prevention (CDC) and its parent organization, the U. S. Department of Health and Human Services, post a variety of communication job openings. The National Cancer Institute within the National Institutes of Health has a variety of initiatives for creating and researching the most effective types of cancer-prevention information (Kreps, 2003). The Health Communication Fellows program places communication experts with government agencies for a period of a 
This is a preprint of an article whose final and definitive form has been published in the Technical Communication Quarterly $17(3) \subseteq$ 2008 Taylor \& Francis; Technical Communication Quarterly is available online at: http://www.informaworld.com doi: 10.1080/10572250802100428

few years (D. Caruso, personal communication, April 2, 2007); internships (as opposed to fellowships) are also available for those who are still completing academic degrees. Many members of the STC's Environmental, Safety, and Health Communication SIG work for local and state agencies.

Work in health communication, whether in print or online formats, also offers communicators the opportunity to help other people by providing information that helps them improve their health, choose among medical treatment options, and increase their knowledge of health and medical issues. This opportunity to make a difference motivates the employees at Alturas, and it is likely to inspire the next generation of health communicators, many of whom will provide information to audiences online.

\section{ACKNOWLEDGEMENTS}

I thank the anonymous reviewers and, especially, the editors of this special issue for their comments, which improved this manuscript substantially. I also thank the management and staff at Alturas for allowing me to observe and learn from them. 


\section{APPENDIX}

\section{Questionnaire:}

1. Please identify your academic degrees (and your major field) and any professional certifications.

2. Please identify any professional associations you belong to.

3. Please identify any professional associations you used to belong to. Why did you drop your membership?

4. What parts of your formal education, structured training experiences (seminars, workshops, conferences, etc.), or other personal development activities have been most valuable to your work at Alturas?

5. What aspects of your previous jobs have been most valuable to you at Alturas?

6. If you were to go to school with the goal of eventually having a job like this one at Alturas, what courses/major fields would you focus on, and why?

7. What best describes the way you view your position at Alturas?

This job is part of an established career path. There are people across the country who also do what I do.

This job is part of a budding career path. There might be other people across the country who also do what I do.

This is a unique position. Only people at Alturas do what I do.

8. Which best describes the way you view your position at Alturas?

I'm a health professional who communicates through writing (and visuals).

I'm a professional who works to create health information.

I'm a writer/communicator who works with health information.

Other (please describe):

9. In your personal professional development, which of the following areas do you focus on the most? Please assign percentages that total 100.

$\%$ Writing/communication skills: skills for creating and editing content for our consumers

$\%$ Management skills/time management skills: skills for doing my work efficiently

$\%$ Content area knowledge: knowledge about health and medicine

$\%$ Other (please identify):

10. Which types of information would be most interesting to you as a Alturas employee? Check all that apply.

For this question, a 'study' is an in-depth, research-based article, while 'best practices' are shorter articles focused on 'how-to' information. 
Studies on effectiveness (or lack thereof) of plain language

Best practices for plain language

Studies on effectiveness (or lack thereof) of online information sites in general

Best practices for online information sites in general

Studies on effectiveness (or lack thereof) of online health information sites

Best practices for online health information sites

Studies on how consumers read online information

Best practices for writing online information that consumers will read

Studies on editing online health information

Best practices for editing online health information

Studies on management practices for developing online content

Best practices in management practices for developing online content

Studies on effectiveness of visuals in online communication

Best practices for visuals in online communication

Studies on effectiveness of interactive multimedia in online communication

Best practices for interactive multimedia in online communication

Studies on other subjects (please identify):

Best practices for other subjects (please identify): 
This is a preprint of an article whose final and definitive form has been published in the Technical Communication Quarterly 17(3)@ 2008 Taylor \& Francis; Technical Communication Quarterly is available online at: http://www.informaworld.com doi: 10.1080/10572250802100428

\section{REFERENCES}

Adler, P. A., \& Adler, P. (1987). Membership Roles in Field Research. Sage University Paper on Quantitative Research Methods, Volume 6. Newbury Park, CA: Sage.

Ament, K. (2003). Single Sourcing: Building Modular Documentation. Norwich, NY: William Andrew.

Anderson, P. V. (2007). Technical Communication: A Reader-Centered Approach. $6^{\text {th }}$ ed. Boston, MA: Thomson Wadsworth.

Applen, J. D. (2002). Technical Communication, Knowledge Management, and XML. Technical Communication 49, 3, pp. 301-313.

Barker, T. T. (1998). Writing Software Documentation: A Task-Oriented Approach. Boston, MA: Allyn \& Bacon.

Barnum, C. M. (2002). Usability Testing and Research. Boston, MA: Longman.

Bicknese, J., Connelly, P., Lantz, K., MacKay, P., \& Snyder, A. (1999a). Explore Personal Characteristics of Biomedical Writers. Biomedical Writing. Retrieved February 25, 2007, from http://www.home.earthlink.net/ rhetrx/bmw/who/personal.htm

-----. (1999b). What Do Biomedical Writers Do? Biomedical Writing. Retrieved April 17, 2007, from http://www.home.earthlink.net/ rhetrx/bmw/what/index.htm

Carter, L. (Ed.) (2003). Making the Leap to Single Sourcing [Special issue]. Technical Communication 50, 3.

Cooper, E. L. (2004). Complementary and Alternative Medicine, When Rigorous, Can Be Science. Evidencebased Complementary and Alternative Medicine 1, 1, pp. 1-4.

Crocco, A. G., Villasis-Keever, M., \& Jadad, A. R. (2002). Analysis of Cases of Harm Associated With Use of Health Information on the Internet. Journal of the American Medical Association 287, 21, pp. $2869-2871$.

Dautermann, J. (1997). Writing at Good Hope: A Study of Negotiated Composition in a Community of Nurses. Vol. 2. ATTW Contemporary Studies in Technical Communication. Greenwich, CT: Ablex.

Davis, M. T. (2001). Shaping the Future of Our Profession. Technical Communication 48, 2, pp. 139-144.

Denny, K. (1999). Evidence-Based Medicine and Medical Authority. Journal of Medical Humanities 20, 4, pp. 247-263.

Dragga, S. (1993). Women and the Profession of Technical Writing: Social and Economic Influences and Implications. Journal of Business and Technical Communication 7, 3, pp. 312-321.

Flammia, M. (1993). The Challenge of Getting Technical Experts to Talk: Why Interviewing Skills Are Crucial to the Technical Communication Curriculum. IEEE Transactions on Professional Communication 36, 3, pp. 124-129.

Fox, S. (2006). Online Health Search 2006. Pew Internet \& American Life Project. Retrieved March 17, 2007, from http://www.pewinternet.org/PPF/r/190/report_display.asp

Freeman, K. (2005). 28,100,000 Hits for "Diabetes" or How E-Health Consumers Navigate Millions of Web Pages to Find Information They Trust. 52nd Annual Conference of the Society for Technical 
This is a preprint of an article whose final and definitive form has been published in the Technical Communication Quarterly $17(3) \subseteq$ 2008 Taylor \& Francis; Technical Communication Quarterly is available online at: http://www.informaworld.com doi: 10.1080/10572250802100428

Communication, Seattle, Wash., May 8-12. Retrieved April 17, 2007, from http://www.stc.org/52ndConf/ session.materials.asp

-----, \& Spyridakis, J. (2004). An Examination of Factors That Affect the Credibility of Online Health Information. Technical Communication 51, 2, pp. 239-263.

Glesne, C. (1999). Becoming Qualitative Researchers: An Introduction. $2^{\text {nd }}$ ed. New York: Longman.

Grama, L. M., Beckwith, M., Bittinger, W., Blais, D., Lollar, C., Middleswarth, A., Noone, M., Price, D., Quint-Kasner, S., Shields, V., \& Wright. L. W. (2005, July-Aug). The Role of User Input in Shaping Online Information From the National Cancer Institute. Journal of Medical Internet Research 7, 3: e25. PubMed Central. Retrieved April 20, 2007, from http://www.pubmedcentral.nih.gov.libproxy. boisestate.edu/articlerender.fcgi?artid=1550662

Hackos, J. T. (1994). Managing Your Documentation Projects. New York: Wiley.

Harris Interactive. (2002). EHealth's influence continues to grow as usage of the Internet by physicians and patients increases. Health Care News 3, 6, 1-7. Retrieved April 20, 2007, from http://www.harrisinteractive.com/news/newsletters/healthnews/ HI_HealthCareNews2003Vol3 Iss06.pdf

Hayhoe, G. F. (1998). Tooltips for the Next Millennium. Technical Communication 45, 2, pp. 155-157.

Health On the Net Foundation. (2007). HONcode: Principles - Quality and trustworthy health information. Retrieved March 15, 2007, from http://www.hon.ch/HONcode/Conduct.html

Hughes, M. (2002). Moving from Information Transfer to Knowledge Creation: A New Value Proposition for Technical Communicators. Technical Communication 49, 3, pp. 275-285.

Internet Healthcare Coalition. (2006). Welcome to the Internet Healthcare Coalition. Retrieved April 20, 2007, from http://www.ihealthcoalition.org

Jeyaraj, J. (2004). Liminality and Othering: The Issue of Rhetorical Authority in Technical Discourse. Journal of Business and Technical Communication 18, 1, pp. 9-38.

Johnson-Sheehan, R. (2005). Technical Communication Today. Boston: Longman.

Jucks, R., \& Bromme, R. (2007). Choice of Words in Doctor-Patient Communication: An Analysis of Health-Related Internet Sites. Health Communication 21, 3, pp. 267-277.

Kreps, G. L. (2003). Opportunities for Health Communication Scholarship to Shape Public Health Policy and Practice: Examples from the National Cancer Institute. In T. L. Thompson, A. Dorsey, K. Miller, \& R. Parrott (Eds.), Handbook of Health Communication (pp. 609-624). Mahwah, NJ: Erlbaum.

Kynell-Hunt, T., \& Savage, G. J. (Eds.) (2003). Power and Legitimacy in Technical Communication: Vol. 1. The Historical and Contemporary Struggle for Professional Status. Amityville, NY: Baywood.

Kynell-Hunt, T., \& Savage, G. J. (Eds.) (2004). Power and Legitimacy in Technical Communication: Vol. 2. Strategies for Professional Status. Amityville, NY: Baywood.

Lay, M. M., Wahlstrom, B. J., Rude, C. D., Selfe, C. L., \& Selzer, J. (2000). Technical Communication. $2^{\text {nd }}$ ed. Boston: McGraw-Hill. 
This is a preprint of an article whose final and definitive form has been published in the Technical Communication Quarterly $17(3) \subseteq$ 2008 Taylor \& Francis; Technical Communication Quarterly is available online at: http://www.informaworld.com doi: 10.1080/10572250802100428

Lee, M. F. \& B. Mehlenbacher. (2000). Technical Writer/Subject-matter Expert Interaction: The Writer's Perspective, the Organizational Challenge. Technical Communication 47, 4, pp. 544-552.

Lincoln, Y. S., \& Guba, E. G. (1985). Naturalistic Inquiry. Beverly Hills, CA: Sage.

Locher, M. A. (2006). Advice Online: Advice-giving in an American Internet Health Column. Pragmatics and Beyond New Series. Amsterdam: John Benjamins.

MacNealy, M. S. (1997). Strategies for Empirical Research in Writing. Boston, MA: Allyn and Bacon.

Markel, M. (2007). Technical Communication. $8^{\text {th }}$ ed. Boston, MA: Bedford/St. Martins.

Miles, M. B., \& A. M. Huberman. (1994). Qualitative Data Analysis: An Expanded Sourcebook. Thousand Oaks, CA: Sage.

Munger, R. (2000). Evolution of the Emergency Medical Services Profession: A Case Study of EMS Run Reports. Technical Communication Quarterly 9, 3, pp. 329-346.

Oermann, M. \& Pasma, J. (2001). Evaluation by consumers of quality care information on the Internet. Journal of Nursing Care Quality 15, 3, pp. 50-58.

Ornatowski, C. M. (1997). Technical Communication and Rhetoric. In K. Staples \& C. Ornatowski (Eds.), Foundations for Teaching Technical Communication: Theory, Practice, and Program Design (pp. 31-51). Greenwich, CT: Ablex.

Peeples, T. (2003). Professional Writing and Rhetoric: Readings from the Field. New York: Longman.

Richards, J. B., Papaioannou, A., Adachi, J. D., Joseph, L., Whitson, H. E., Prior, J. C., \& Goltzman, D. (2007). Effect of Selective Serotonin Reuptake Inhibitors on the Risk of Fracture. Archives of Internal Medicine 167, pp. 188-194.

Rockley, A. (2003). Managing Enterprise Content: A Unified Content Strategy. Indianapolis: New Riders.

Ryan, C. (2005). Struggling to Survive: A Study of Editorial Decision-Making Strategies at MAMM Magazine. Journal of Business and Technical Communication 19, 3, pp. 353-376.

Sackett, D. L., \& Rosenberg, W. M. C. (1995). The need for evidence-based medicine. Journal of the Royal Society of Medicine 88, pp. 620-624.

Savage, G. J., and D. L. Sullivan. (2001). Writing a Professional Life: Stories of Technical Communicators On and Off the Job. Allyn \& Bacon Series in Technical Communication. Boston: Allyn \& Bacon.

Scope. (n.d.). Journal of Medical Internet Research. Retrieved April 20, 2007, from http://www.jmir.org/cms/view/jmir_home:scope

Spilka, R. (2002). Becoming a Profession. In B. Mirel \& R. Spilka (Eds.), Reshaping Technical Communication: New Directions and Challenges for the $21^{\text {st }}$ Century (pp. 97-109). Mahwah, NJ: Erlbaum.

Tjora A., Tran T., \& Faxvaag A. (2005). Privacy vs usability: a qualitative exploration of patients' experiences with secure Internet communication with their general practitioner. Journal of Medical Internet Research 7, 2:e15. Retrieved October 19, 2007, from http://www.pubmedcentral.nih.gov.libproxy.boisestate.edu/ articlerender.fcgi?artid $=1550647$ 
This is a preprint of an article whose final and definitive form has been published in the Technical Communication Quarterly $17(3) \subseteq$ 2008 Taylor \& Francis; Technical Communication Quarterly is available online at: http://www.informaworld.com doi: 10.1080/10572250802100428

Turns, J., \& Wagner, T. S. (2002). Listening to the Learners: A Case Study in Health Information Website Design. Proceedings of the 49th Annual Conference of the Society for Technical Communication, Nashville, TN, May 5-8. Retrieved January 30, 2007, from

http://www.stc.org/confproceed/2002/PDFs/STC49-00042.pdf

URAC. (2007).Health Content and Personal Health Management Providers Accreditation Standards Summary. Retrieved March 15, 2007, from http://www.urac.org/programs/prog_accred_hcp_ss.aspx?navid=accreditation\& pagename=prog_accred_HCP

Whitburn, M. D. (2000). Rhetorical Scope and Performance: The Example of Technical Communication. ATTW Contemporary Studies in Technical Communication, Vol. 13. Stamford, CT: Ablex.

Wick, C. (2000). Knowledge Management and Leadership Opportunities for Technical Communicators. Technical Communication 47, 4, pp. 515-529.

Williamson, K. (2005). Where One Size Does Not Fit All: Understanding the Needs of Potential Users of a Portal to Breast Cancer Knowledge Online. Journal of Health Communication 10, pp. 567-580.

Womersley, T. (2004, 3 March). Stroke risk halts HRT study. The Scotsman. Retrieved April 17, 2007, from http://news. scotsman.com/topics.cfm?tid=466\&id=247982004

Zimmerman, D. E., Akerelrea, C. \& Buller, D. (2003). Lessons Learned from Building a Health Web Site: Implications for Technical Communicators. Proceedings of the 50th Annual Conference of the Society for Technical Communication, Dallas, TX, May 18-21. Retrieved January 30, 2007, from http://www.stc.org/ConfProceed/ 2003/PDFs/STC50-046.pdf 